\title{
The lateral preference inventory for measurement of handedness, footedness, eyedness, and earedness: Norms for young adults
}

\author{
STANLEY COREN \\ University of British Columbia, Vancouver, British Columbia, Canada
}

\begin{abstract}
The Lateral Preference Inventory is a brief, 16 -item questionnaire, which validly measures hand, foot, eye, and ear preference. Normative data is presented for 3,307 subjects, ranging in age from 17 to 35 years. Data is separated by sex, since females are found to be more right-sided than are males for hand, foot, and ear. Data are presented in a format that should allow various scoring and coding criteria to be applied. These norms could serve as a reference or control comparison for measures of laterality taken on clinical or other targeted groups. A copy of the inventory appears in the Appendix.
\end{abstract}

While there are a number of self-report inventories for the measurement of handedness (see Porac \& Coren, 1981 , for a review), very few questionnaires have been developed that can provide a quick, valid measure of all four indexes of lateral preference: handedness, footedness, eyedness and earedness. A series of behaviorally validated items have been gathered together to form the Lateral Preference Inventory (LPI), which is a brief but valid and reliable measure of hand, foot, eye, and ear preference.

The LPI is reproduced as an Appendix to this report. Despite the fact that this inventory involves only 16 items (4 items per subscale) and takes only 2 or $3 \mathrm{~min}$ to complete, experiments have demonstrated a $92 \%$ concordance between self-reports on the LPI items and direct behavioral performance testing on these actions, averaged across the full set of four lateral preferences (Coren, Porac, \& Duncan, 1979; Porac \& Coren, 1981). The behavioral validity is highest for the four-item handedness subscale (at $97 \%$ concordance), with test-retest reliabilities over a period of a full year averaging $98 \%$ (Coren \& Porac, 1978).

The LPI (or its handedness subscale) has been used to show reliable laterality differences in a variety of studies, including the relationship between laterality and birth stress (Coren, Searleman, \& Porac, 1982), age effects on

\footnotetext{
This research was supported in part by grants from the British Columbia Health Care Research Foundation, the Natural Sciences and Engineering Research Council of Canada, and the Medical Research Council of Canada. I would like to acknowledge the assistance of David Wong, Wayne Wong, Joan Coren, Geof Donelly, Steven Gault, Lynda Berger, and the staff of the Human Neuropsychology and Perception Laboratory of the University of British Columbia, who assisted in the collection of these data. For reprints or other correspondence, contact S. Coren, Department of Psychology, University of British Columbia, 2136 West Mall, Vancouver, British Columbia, V6T 1Z4, Canada (fax: 604-822-6923).
}

lateral preference (Porac, Coren, \& Duncan, 1980), genetic factors in lateral preferences (Coren \& Porac, 1980), the effects of lateral preference patterns on sports (Porac \& Coren, 1981), and cognitive abilities (Coren \& Porac, 1982). The handedness subscale has been used to explore relationships between handedness and physical maturation (Coren, Searleman, \& Porac, 1986), sleep (Coren \& Searleman, 1987), accident susceptibility (Coren, 1989), the effects of maternal age at parturition on handedness (Coren, 1990), and relationships to transsexuality (Watson \& Coren, 1992).

For many research purposes, it is useful to have an accurate picture of the distribution of lateral preferences as measured by a particular instrument. Large sample norms from a young adult sample would provide the most useful base of comparison, serving as a reference point to monitor aging-related changes in lateral preference patterns. It could also serve as a baseline to assess the distribution of lateral preferences in various clinical subgroups. To provide data on the prevalence of lateral preferences as measured by the LPI, the following study was conducted.

\section{METHOD}

The sample consisted of 3,307 nonselected volunteers (1,932 females and 1,375 males). The subjects ranged in age from 17 to 35 years and were recruited from the campus of the University of British Columbia, in Vancouver, Canada. Each subject received the Lateral Preference Inventory (reproduced in the Appendix), which consists of 16 items to assess hand, foot, eye, and ear preference. Each item requires the response of "left," "right," or "either."

\section{RESULTS AND DISCUSSION}

In dealing with lateral preference data, various investigators use different criteria to determine left- versus right-sidedness. Some simply dichotomize the data for each scale, thus (using handedness as an example) a per- 
son who performs more actions with the left hand would be classified as left-handed. Others require more stringent criteria. A common "stringent" classification scheme is to contrast consistent right-handers (all actions with the right hand) to those who are left or ambidextral on any action (which would be classified as "non-right-handers" or "adextrals"). Other researchers categorize data into consistent right-handers, mixed right-handers, mixed lefthanders, and consistent left-handers. Several other classification schemes exist as well. For example, Coren and Porac (1980) and Searleman, Porac, and Coren (1989) suggest that both direction and strength are important and recommend use of a continuous measure giving both side and consistency of lateral preference. In recognition of these various handedness criteria and requirements, the data from the LPI are presented in a form that can be easily converted into any of these formats.

Data are simply scored for each four-item scale as ( $R-L)$, where $R$ is the number of "right" responses and $\mathrm{L}$ is the number of "left." This means that we have scales that go from -4 to 4 , with -4 meaning consistent leftsidedness and 4 meaning consistent right-sidedness for any index. A score of zero would indicate ambilaterality. Table 1 gives the LPI scores in percentages broken down by sex.

To use these norms for the various sidedness criteria merely takes appropriate cumulation of the percentages. For example, to dichotomize into left- versus right-sided, Porac and Coren (1981) recommend using zero as the cut point and including the ambilaterals with the lefts. Thus, we would have $9.2 \%$ left-handed females (summing -4 through 0 ) by this criterion. To dichotomize females into consistent right-handed versus non-right-handed, one would simply separate the LPI individuals with a score of 4 , giving $79.8 \%$ right-handers versus 20.2 non-righthanders (summing -4 through 3 ). Mixed lefts could be defined as LPI scores of 0 though -3 (e.g., $5.2 \%$ of females); mixed right could be defined as scores of 1 though 3 (11.1\% of females). Other coding schemes are, of course, possible.
Table 2

Consistency of Sidedness, Measured as the Number of LPI Indexes that are Right-Sided in the Test Population

\begin{tabular}{ccc}
\hline $\begin{array}{c}\text { Number of Indexes } \\
\text { that are Right-sided }\end{array}$ & Females & Males \\
\hline 0 & 4.3 & 4.1 \\
1 & 3.2 & 6.0 \\
2 & 12.1 & 14.5 \\
3 & 31.8 & 32.9 \\
4 & 48.6 & 42.5 \\
\hline
\end{tabular}

Note-Entries for females and males represent percentages.

The LPI data presented here replicate the usually expected sex differences, with females showing more rightsidedness than males for all indexes except eye preference. Using the simple left-right dichotomy (cutting at 0 , with LPI $=0$, included with the lefts), females are more likely to be right-handed $[90.8 \%$ vs. $88.2 \%$; $\left.\chi^{2}(1)=5.99, p<.05\right]$. Females are also more often right-footed $\left[88.9 \%\right.$ vs. $83.9 \% ; \chi^{2}(1)=17.63, p<$ $.001]$ and right-eared $\left[67.4 \%\right.$ vs. $60.5 \% ; \chi^{2}(1)=16.62$, $p<.001]$. However, there is no significant sex difference in eye preference $\left[70.0 \%\right.$ vs. $71.3 ; \chi^{2}(1)=0.60$, n.s.].

One question that might be asked, which cannot be answered directly from Table 1, pertains to the agreement among sidedness indexes. For example, how many individuals are right-sided on all four indexes? Table 2 shows the percentage of individuals with zero to 4 right-sided preferences, where each preference is scored using the simple dichotomy at zero, as above. As might be expected from our earlier discussion, females are more likely to be consistently right-sided over all four indexes of sidedness $(48.6 \%$ vs. $42.5 \% ; z=3.47, p<.001)$.

It is hoped that the normative data provided here may prove to be a useful indication of the distribution of lateral preferences in North American young adults. The size of the sample is sufficiently large to provide a degree of stability and should allow various generalizations and comparisons if the LPI is used on various groups of the-

Table 1

Lateral Preference Inventory Scores for a Sample of

3,307 Subjects, Presented by Sex and Sidedness Index

\begin{tabular}{|c|c|c|c|c|c|c|c|c|}
\hline \multirow[b]{2}{*}{ LPI Score } & \multicolumn{2}{|c|}{ Handedness } & \multicolumn{2}{|c|}{ Footedness } & \multicolumn{2}{|c|}{ Eyedness } & \multicolumn{2}{|c|}{ Earedness } \\
\hline & Female & Male & Female & Male & Female & Male & Female & Male \\
\hline-4 & 4.0 & 4.7 & 2.2 & 1.9 & 14.7 & 14.0 & 10.1 & 11.2 \\
\hline-3 & 0.5 & 0.3 & 0.7 & 1.5 & 1.9 & 1.7 & 2.1 & \\
\hline-2 & 2.1 & 2.7 & 2.0 & 2.4 & 6.0 & 5.2 & 6.9 & 8.7 \\
\hline-1 & 0.2 & 0.4 & 1.3 & 2.5 & 1.8 & 2.0 & 3.2 & 3. \\
\hline 0 & 2.4 & 3.7 & 4.9 & 7.9 & 5.6 & 5.8 & 10.2 & 13.1 \\
\hline 1 & 0.6 & 1.0 & 6.5 & 8.5 & 2.5 & 4.0 & 7.1 & 6.8 \\
\hline 2 & 6.9 & 9.5 & 16.1 & 21.0 & 7.1 & 8.1 & 12.6 & 15.6 \\
\hline 3 & 3.6 & 3.8 & 15.8 & 15.6 & 7.5 & 7.7 & 9.2 & 9.0 \\
\hline 4 & 79.8 & 73.9 & 50.4 & 38.8 & 52.9 & 51.5 & 38.6 & 29.2 \\
\hline
\end{tabular}

Note-Each entry represents the percentage of the sample with that LPI score. Scores range from -4 (consistent left) to 4 (consistent right). 
oretical interest. These norms could potentially be used to assess the degree of elevation of sinistrality in specific clinical groups, such as those with histories of various birth stressors or other early pathology, using the present sample as a reference or control group. Of course, for such comparisons to be valid, the item wordings and response alternatives must be the same as those in the Lateral Preference Inventory described in the Appendix. The 16 items that make up the LPI are sufficiently brief and self-explanatory so that they can easily be incorporated into existing inventories, to allow a quick assessment of all four dimensions of laterality. The handedness subscale, comprised of only four items, can easily be inserted into a variety of other information-gathering instruments.

\section{REFERENCES}

COREN, S. (1989). Left-handedness and accident-related injury risk. American Journal of Public Health, 79, 1040-1041.

CoRen, S. (1990). Relative risk of left-handedness in offspring as a function of maternal age at parturition. New England Journal of Medicine, 322, 1673.

Coren, S., \& Porac, C. (1978). The validity and reliability of selfreport items for the measurement of lateral preference. British Journal of Psychology, 69, 207-211.

Coren, S., \& Porac, C. (1980). Family patterns in four dimensions of lateral preference. Behavior Genetics, 10, 333-348.

Coren, S., \& Porac, C. (1982). Lateral preference and cognitive skills: An indirect test. Perceptual \& Motor Skills, 54, 787-792.

Coren, S., Porac, C., \& Duncan, P. (1979). A behaviorally validated self-report inventory to assess four types of lateral preference. Journal of Clinical Neuropsychology, 1, 55-64.

Coren, S., \& Searleman, A. (1987). Left-sidedness and sleep difficulty: The alinormal syndrome. Brain \& Cognition, 6, 184-192.

Coren, S., Searleman, A., \& Porac, C. (1982). The effects of specific birth stressors on four indexes of lateral preference. Canadian Journal of Psychology, 36, 478-487.

Coren, S., Searleman, A., \& Porac, C. (1986). Rate of physical maturation and handedness. Developmental Neuropsychology, 2, 17-23.

PORAC, C., \& COREN, S. (1981). Lateral preferences and human behavior. New York: Springer-Verlag.

Porac, C., Coren, S., \& Duncan, P. (1980). Life-span age trends in laterality. Journal of Gerontology, 35, 715-721.

Searleman, A., Porac, C., \& Coren, S. (1989). The relationship between birth order, birth stress, handedness and lateral preference: A critical review. Psychological Bulletin, 105, 397-408.

Watson, D. B., \& Coren, S. (1992). Left-handedness in male to female transsexuals. Journal of the American Medical Association, 267, 1342 .

\author{
APPENDIX \\ The Lateral Preference Inventory
}

Simply read each of the questions below. Decide which hand, foot, etc. you use for each activity and then put a check mark next to the answer that describes you the best. If you are unsure of any answer, try to act out the action.

1. With which hand do you draw?

2. Which hand would you use to throw a ball to hit a target?

3. In which hand would you use an eraser on paper?

4. Which hand removes the top card when you are dealing from a deck?

5. With which foot would you kick a ball to hit a target?

6. If you wanted to pick up a pebble with your toes, which foot would you use?

7. Which foot would you use to step on a bug?

8. If you had to step up onto a chair, which foot would you place on the chair first?

9. Which eye would you use to look through a telescope?

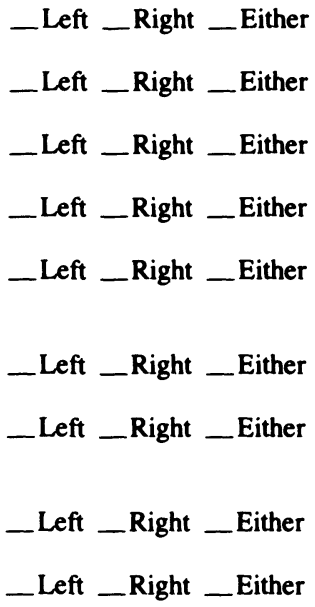

10. If you had to look into a dark bottle to see how full it was, which eye would you use?

11. Which eye would you use to peep through a keyhole?

12. Which eye would you use to sight down a rifle?

13. If you wanted to listen in on a conversation going on behind a closed door, which ear would you place against the door?

14. Into which ear would you place the earphone of a transistor radio?

15. If you wanted to hear someone's heartbeat which ear would you place against their chest?

16. Imagine a small box resting on a table. This box contains a small clock. Which ear would you press against the box to find out if the clock was ticking?

Scoring Instructions:

Items 1-4 are handedness, 5-8 are footedness, 9-12 are eyedness, and 13-16 are earedness. For each 4-item subscale, compute (R-L), where $R$ is the number of "right" responses and $L$ is the number of "left" responses. 